\title{
Cytologische Studien an Trichocysten
}

\section{Feinstruktur und Funktionsmodus der Trichocysten des Flagellaten Oxyrrbis marina und des Ciliaten Pleuronema marinum"}

\author{
K. HausmanN \\ Institut fïr Cytologie und Mikromorphologie der Universität Bonn; \\ Bonn, Bundesrepublik Deutschland
}

\begin{abstract}
Cytological studies on trichocysts. VI. Fine structure and mode of function of trichocysts in the flagellate Oxyrrbis marina and the ciliate Pleuronema marinum. The dinoflagellate Oxyrrbis marina and the ciliate Pleuronema marinum were investigated in regard to their trichocysts. In O. marina the resting trichocyst consists of shaft and tip; while the tip exhibits a tubulous inner structure, the material of the shaft possesses a longitudinally oriented striation of $80 \AA$, subdivided into periods of $40 \AA$. The resting trichocyst of $P$. marinum has a paracrystalline character with a periodicity of $65-80 \AA$. The elongated trichocyst of $O$. marina is characterized by a cross-striation of main periods of $680 \bar{A}$, subdivided into subperiods of 160-170 $\AA$. It can be demonstrated that the smallest structural components of the shaft are filaments with a diameter of $10 \AA$, lying parallel to the long axis of the trichocysts. The elongated trichocyst of $P$. marinum possesses a cross-striation with a periodicity of $560 \AA$. Filaments measuring 10-15 $\AA$, which are arranged largely parallel to the long axis of the trichocyst, form an ordered network similar to the structure of the elongated Paramecium trichocyst. Inhibited trichocysts of O. marina and P. marinum reveal that discharge of trichocysts can be interpreted as sudden elongation of one paracrystalline state into another. These findings are compared with previous results obtained on the Paramecium trichocyst. These three trichocyst types possess similar features, indicating that the elongation of $O$. marina and P. marinum trichocysts also represents an unfolding process of preformed structures.
\end{abstract}

\section{EINLEITUNG}

Ein großer Teil der Protisten besitzt Trichocysten: Organelle, die, dicht unter der Pellicula gelegen, auf verschiedenartigste Reize hin unter Veränderung ihrer Morphologie den Zellkörper verlassen können (Hausmann 1972a, Hovasse 1965, 1969, KRÜGER 1936). Bei den Ciliaten sind drei in Funktion und Morphologie unterschiedliche Trichocysten nachgewiesen: (1) Mucocysten (= Protrichocysten); (2) Spindeltrichocysten; (3) Toxicysten (= Nesselkapseltrichocysten). Die Mucocysten und Spindeltrichocysten sind auf Grund neuerer Untersuchungen ihres Baues und ihrer Funktionsweise zu einer Gruppe zusammenzufassen und somit von den Toxicysten abzu-

* Die Deutsche Forschungsgemeinschaft unterstützte die Untersuchung durch die Sachbeihilfe WO 20/21. 
grenzen (Hausmann 1972b, 1973a, b, Hausmann et al. 1972a, b, Krüger 1931a, b, 1934b, Stockem \& Wohlfarth-Bottermann 1970, Wohlfahrt-Bottermann \& PfefFerkorn 1953).

Auch Flagellaten besitzen unterschiedlich gebaute Trichocysten (CHATton 1914, Chatton \& Hovasse 1944, Greuet 1971, Hovasse 1963, Krüger 1934a, Mrgnot et al. 1970, Schuster 1966, 1970). Unter anderem sind Strukturen beschrieben, die eine gewisse Ahnlichkeit mit den Spindeltrichocysten der Ciliaten aufweisen. Besonders wurden diese Organelle bei einer Anzahl von Dinoflagellaten untersucht (ANderson 1962, Bouck \& SweEney 1966, Dodge \& CRAwford 1968, 1971a, b, Dragesco 1952, Dragesco \& Hollande 1965, Grell 1968, Messer \& Ben-Shaul 1970, 1971, SwEENEY \& BoucK 1966). Es zeigte sich, daß bei diesen Trichocysten, ähnlich wie bei einem Teil der Ciliaten-Spindeltrichocysten (Hausmann 1971, JAkUs 1945, KRÜGER 1930, Wohlfarth-Bottermann 1953), ein Schaft und eine Spitze unterschieden werden können. Während der ruhende Schaft durchweg einen parakristallinen Feinbau besitzt, besteht die Spitze bei den meisten Flagellaten aus einem Büschel von tubulären oder filamentösen Strukturen.

Im folgenden sollen bei dem Dinoflagellaten Oxyrrbis marina und dem holotrichen Ciliaten Pleuronema marinum mit Hilfe der Schrägbeschattungs-, der Negativstaining- und der Schnitt-Technik die Feinstrukturen der ruhenden und ausgeschiedenen Trichocysten sowie der Funktionsmechanismus dieser Organelle untersucht und die Ergebnisse im Zusammenhang mit den neuen Befunden an Spindeltrichocysten von Paramecium caudatum diskutiert werden.

\section{MATERIAL UND METHODEN}

Der Dinoflagellat Oxyrrhis marina wurde aus Dauerkulturen*, der Ciliat Pleuronema marinum aus der Spritzwasserzone des Helgoländer Nordwattes entnommen und wie folgt präpariert:

(1) Dünnschnitt-Technik. Die Zellen wurden durch eine Zentrifugation (1000 U/min, $5 \mathrm{~min}$ ) angereichert und im Zentrifugenglas mit $5 \%$ Glutaraldehyd (Sabatini et al. 1963) bzw. 3\% OsO $4 / 2 \% \mathrm{~K}_{2} \mathrm{Cr}_{2} \mathrm{O}_{7}$ (Wohlfahrt-BotTermann 1957) 20 min fixiert. Nach gründlichem Waschen mit Puffer bzw. Ringer-Lösung (RomeIs $\$ 119,1968)$ und Entwässerung über eine Alkoholreihe steigender Konzentration mit Nachkontrastierung durch $1 \%$ Phosphorwolframsäure (PWS) und 0,5\% Uranylacetat (UA) in 70\% Alkohol (Wohlfarth-Bottermann 1957) wurden die Proben in StyrolMethacrylat eingebettet (Kushida 1961, STOckem \& Komnick 1970). Die Dünnschnitte wurden an einem LKB-Mikrotom hergestellt.

(2) Negativ-staining-Technik. Für die Negativ-staining-Technik wurden die Tiere durch eine intensivere Zentrifugation (4000 U/min, $15 \mathrm{~min}$ ) zu einem Sediment vereinigt. Eine Resuspension des Pellets in einigen Millilitern Aqua bidest. bedingte ein weitgehendes Zerplatzen der Zellen, wodurch ruhende und aus-

* Dr. G. Uhutg, Biologische Anstalt Helgoland, stellte freundlicherweise für die vorliegende Untersuchung Dauerkulturen von Oxyrrbis marina zur Verfügung. 
geschleuderte Trichocysten freigesetzt wurden. Die Kontrastierung der Präparate mit PWS bzw. UA erfolgte nach einer bereits ausfuhrlich beschriebenen Methode (HAusMANN et al. 1972a, Müller 1972, Rermer 1967, Stockem 1970).

(3) Schrägbeschattungs-Technik. Ein Teil des für die Negativstaining-Technik vorbereiteten Materials wurde anstelle der Negativkontrastierung in der üblichen Art simultan mit Platin-Kohlenstoff unter einem Winkel von $20^{\circ}$ schrägbeschattet (Edwards-Bedampfungsanlage Typ E 12 E 2).

Sämtliche Präparate wurden mit einem Philips EM 300 untersucht.

\section{ERGEBNISSE}

Da wegen der hohen Massendicke intakte Protisten nicht direkt durchstrahlbar sind, ist eine Vorbehandlung des Materials für die Suspensions-Technik notwendig. Als sehr günstig und einfach erweist es sich bei Meerwasserprotozoen, die durch eine Zentrifugation angereicherten Zellen Aqua bidestillata auszusetzen (vgl. Abschnitt über Material und Methoden). Dieser Prozeß bewirkt ein schnelles Zerplatzen der Tiere, so daß die Zellorganelle freigesetzt werden. Nach sofort folgender Negativkontrastierung mit PWS bzw. UA lassen sich in den Suspensionspräparaten neben ruhenden und ausgeschleuderten Trichocysten auch solche $\mathrm{Z}_{\text {wischenstadien finden, die Rückschlüsse }}$ auf den Funktionsablauf dieser Organelle ermöglichen.

\section{Oxyrbis marina}

Als erstes sollen die Ruheformen (Abb. 1), dann die Strukturverhältnisse ausgeschleuderter Trichocystenschäfte (Abb. 2 und 3) und schließlich die nicht zur völligen, sondern zur unterschiedlich weiten Streckung gelangten Stadien besprochen werden (Abb. 4 und 5).

\section{Rubende Trichocysten}

Im Ruhezustand besitzen die Trichocysten eine Länge von 1,5-2 $\mu \mathrm{m}$ und eine Breite von $0,3-0,4 \mu \mathrm{m}$ (Abb. 1 a). Bei einer schwachen Vergrößerung von PWSkontrastierten Präparaten sind im Schaft (Abb. 1 a, Sch) keine auffälligen Strukturdetails auszumachen. In der Spitze (Abb. 1 a, Sp) erkennt man jedoch eine längsausgerichtete, tubuläre Struktur.

Bei dieser Vergrößerungsstufe wird noch nicht deutlich, daß die gesamte Trichocyste von einer Membran umbüllt wird. Wie im weiteren noch gezeigt werden soll (vgl. den Abschnitt über gehemmte Trichocysten), beginnt die Abgabe des Trichocystenmaterials mit einem Aufbrechen dieser Membran, indem sich eine Kappe loslöst, die die Spitze umgibt. Isolierte und deshalb gut durchstrahlbare Spitzenkappen lassen ein regelmäßiges Muster erkennen ( $\mathrm{Abb}, 1 \mathrm{~b}$ ): Zwei in Längs- und Querrichtung verlaufende, aufeinander senkrecht stehende Streifungen ergeben ein gleichförmiges Gitterwerk. Dieses Muster ist nur auf den Kappen nachzuweisen. Isolierte Tricho- 

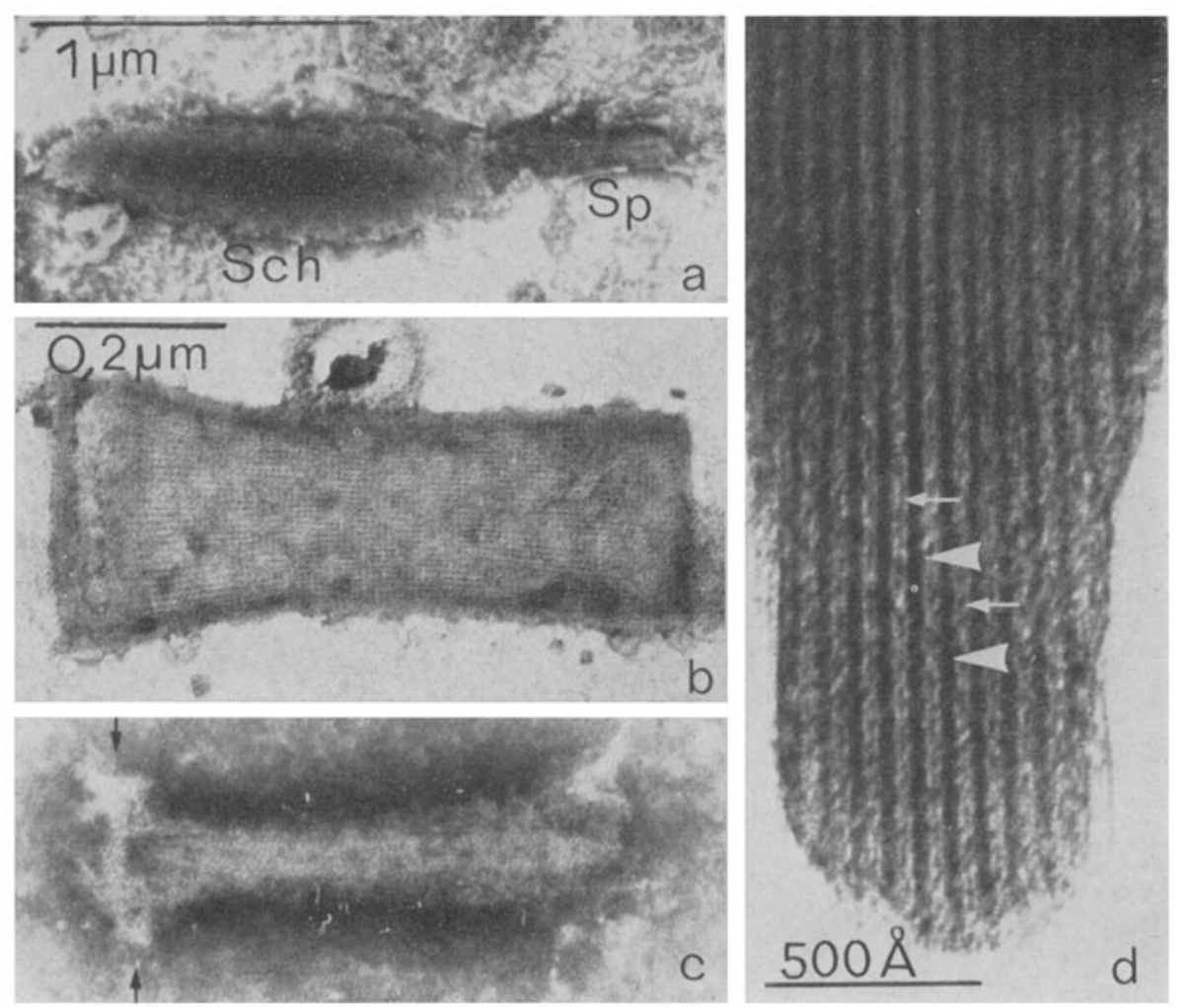

Abb. 1: Ruheformen der Trichocysten von Oxyrrbis marina, a Das Obersichtsbild zeigt die beiden Strukturkomponenten der Trichocyste: Schaft (Sch) und Spitze (Sp) (1\% PWS; $35000: 1)$. b Feinstruktur einer isolierten Spitzenhülle (1\% PWS; $100000: 1$ ). c Isolierte Spitzeninnenstruktur mit längsausgerichtetem Material, das an der Basis verbreitert ist (Pfeile) $(1 \%$ PWS; $100000: 1)$. d Längsverlaufende Strukturen im ruhenden Trichocystenschaft bei hoher Vergrößserung. Die Hauptperiode von $80 \AA$ (Pfeilspitzen) wird in den hellen Banden durch eine weitere Streifung aufgeteilt (kleine Pfeile) (1\% UA; 445000:1)

cystenhüllen scheinen strukturlos zu sein (vgl. Abb. $5 \mathrm{~d}-\mathrm{f}$ ). Das Spitzeninnere besteht aus längsausgerichtetem Material, das sich zur Basis hin verbreitert (Abb. 1 c, Pfeile).

Nach einer Kontrastierung mit PWS treten bei den ruhenden Trichocysten nur die beschriebenen Strukturdetails in Erscheinung. Durch die Anwendung von UA als

Abb. 2: Gestreckte Trichocysten von Oxyrrbis marina. a Bereits im Ubersichtsbild gestreckter Trichocysten erkennt man die Querstreifung des Schaftes (Pfeile) (1\% PWS; $30000: 1)$. $b$ Im Schnittbild scheint die Streifung eine Periode von 160-165 Å zu besitzen (Pfeilspitzen), wobei an einigen Stellen jedoch Unregelmäßigkeiten in den dunklen Banden auftreten können (Pfeile) (5\% Glutaraldehyd; $150000: 1)$. c Im Querschnitt sind die Trichocystenschäfte rechteckig mit Kantenlängen von $500-600 \AA$ (5\% Glutaraldehyd; $150000: 1)$. d Im Negativkontrast erscheint nach PWS-Behandlung eine Hauptperiode von $680 \AA$ (große Pfeilspitzen), die durch drei Unterperioden aufgeteilt wird (kleine Pfeilspitzen) (1\% PWS; 150 000:1). $e$ Nach UA-Kontrastierung tritt die Hauptperiode distinkter hervor (große Pfeilspitzen). Die Unterperioden (kleine Pfeilspitzen) sind teilweise nochmals untergliedert (Pfeile) (1\% UA; 150000:1) (d und $e$ vgl. HausmanN \& STOCKEM 1973) 

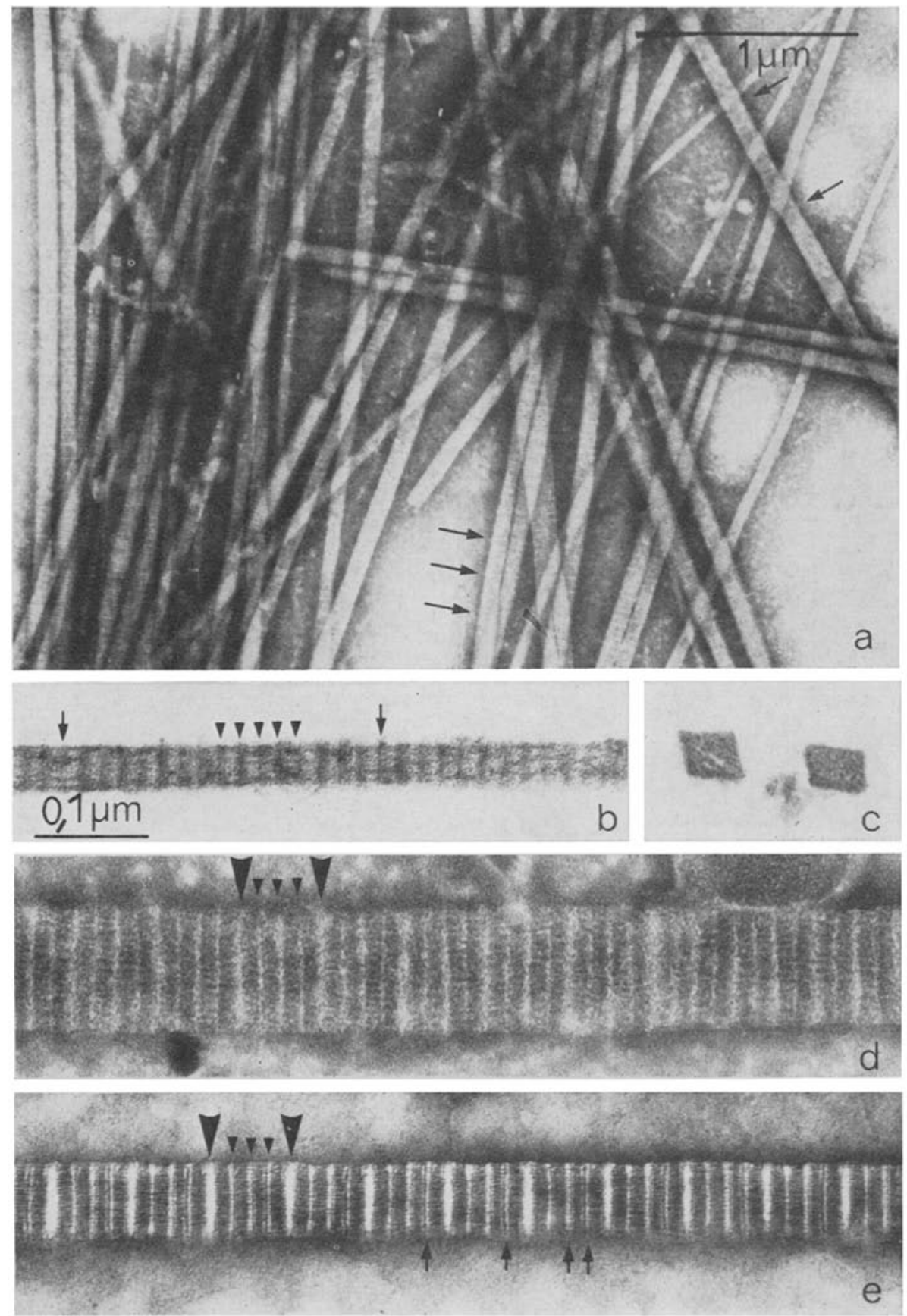

Abb. 2 
Kontrastierungsmittel hingegen können im Schaft weitere Einzelheiten zur Darstellung gebracht werden. Parallel zur Längsachse wird eine aus hellen und dunklen Banden bestehende Streifung sichtbar, die in regelmäßigen Abständen von $80 \AA$ wiederkehrt (Abb. $1 \mathrm{~d}$, Pfeilspitzen), ein Strukturaspekt, der aus den Schnittuntersuchungen bekannt ist (DODgE \& CRAwFord 1971a). Über die Schnituntersuchung hinaus erscheint im Negativ-staining-Präparat in den hellen Streifen eine feine, dunkle Struktur, die die hellen Banden in zwei gleichgroße Teile aufgliedert (Abb. 1d, kleine Pfeile). Diese Erscheinung wird besonders im hinteren, sich verjüngenden Ende des Schaftes deutlich, da hier das Material nicht mehr so dicht vorliegt wie in den Mittelregionen.

\section{Gestreckte Trichocysten}

In den negativ kontrastierten Suspensionen sind oft Bündel von gestredkten Trichocysten zu beobachten (Abb. 2 a). Bereits in der Übersicht erkennt man eine regelmäßige Querstreifung (Abb. 2 a, Pfeile), die sich über die gesamte Länge des Schaftes erstreckt. Die Schaftbreite kann bei gleichbleibender Periode zwischen 0,1 und 0,07 $\mu \mathrm{m}$ variieren. In längsgeschnittenen Trichocysten tritt die periodische Streifung ebenfalls auf (Abb. 2 b, Pfeilspitzen). Hier wird sie von mehr oder minder gleichförmigen hellen und dunklen Banden gebildet, die im Abstand von 160-165 $\AA$ wiederkehren. An einigen Stellen scheinen die dunklen Streifen unregelmäßig und unterschiedlich strukturiert (Abb. 2 b, Pfeile). Diese Erscheinung ist nicht auf eine durch den Fixierungs- und Einbettungsvorgang bedingte artefizielle Veränderung des Materials zurückzuführen, sondern als eine tatsächlich gegebene Struktur anzusehen, wie höhere Vergrößerungen des negativ kontrastierten Materials beweisen (Abb. 2 d, e). Die Kontrastierung mit PWS zeigt bereits andeutungsweise eine durch breitere Banden gekennzeichnete Hauptperiode von $680 \AA$ (Abb. 2 d, große Pfeilspitzen). Diese Hauptperiode wird in drei Unterperioden aufgegliedert (Abb. $2 \mathrm{~d}$, kleine Pfeilspitzen), die nach einer PWS-Kontrastierung gleichartig erscheinen. Das Material liegt bei dieser Kontrastierungsart jedoch nicht mehr in einem annähernd nativen Zustand vor. Die gestreckten Trichocystenschäfte sind nämlich, wie es die Schnittbilder zeigen, im Querschnitt rechtedkig (Abb. 2 c). Die Kantenlängen betragen ungefähr 500-600 $\AA$. Die mit PWS kontrastierten Schäfte hingegen haben eine Breitenausdehnung von über $1000 \AA$ A. Aus diesen Breitendifferenzen muß geschlossen werden, daß bei der Behandlung mit PWS eine beträchtliche Desintegration des Trichocystenmaterials eingetreten ist und somit keine Vitalstrukturen mehr vorliegen.

Nach Anwendung von UA erscheint der Trichocystenschaft bei gleichbleibenden Periodenabständen schmaler (Abb. 2 e). Mit einer Breite von 600-650 $\AA$ entspricht er fast den Ergebnissen der Schnittuntersuchung. Es treten die Hauptperioden von $680 \AA$ A deutlicher hervor (Abb. 2 e, große Pfeilspitzen). Sie setzen sich somit klar von den Unterperioden $a b$, die nun im Vergleich zu den Hauptperioden offenbar schmaler sind (Abb. 2 e, kleine Pfeilspitzen). Die Unterperioden sind teilweise nochmals untergliedert (Abb. 2 e, Pfeile). Bei den breiten Banden der Hauptperiode wäre es denkbar, daß es sich um artefizielle Veränderungen des Musters handelt, indem nach erfolgter Kontrastierung die Trichocysten an diesen Stellen zerrissen und somit elek- 

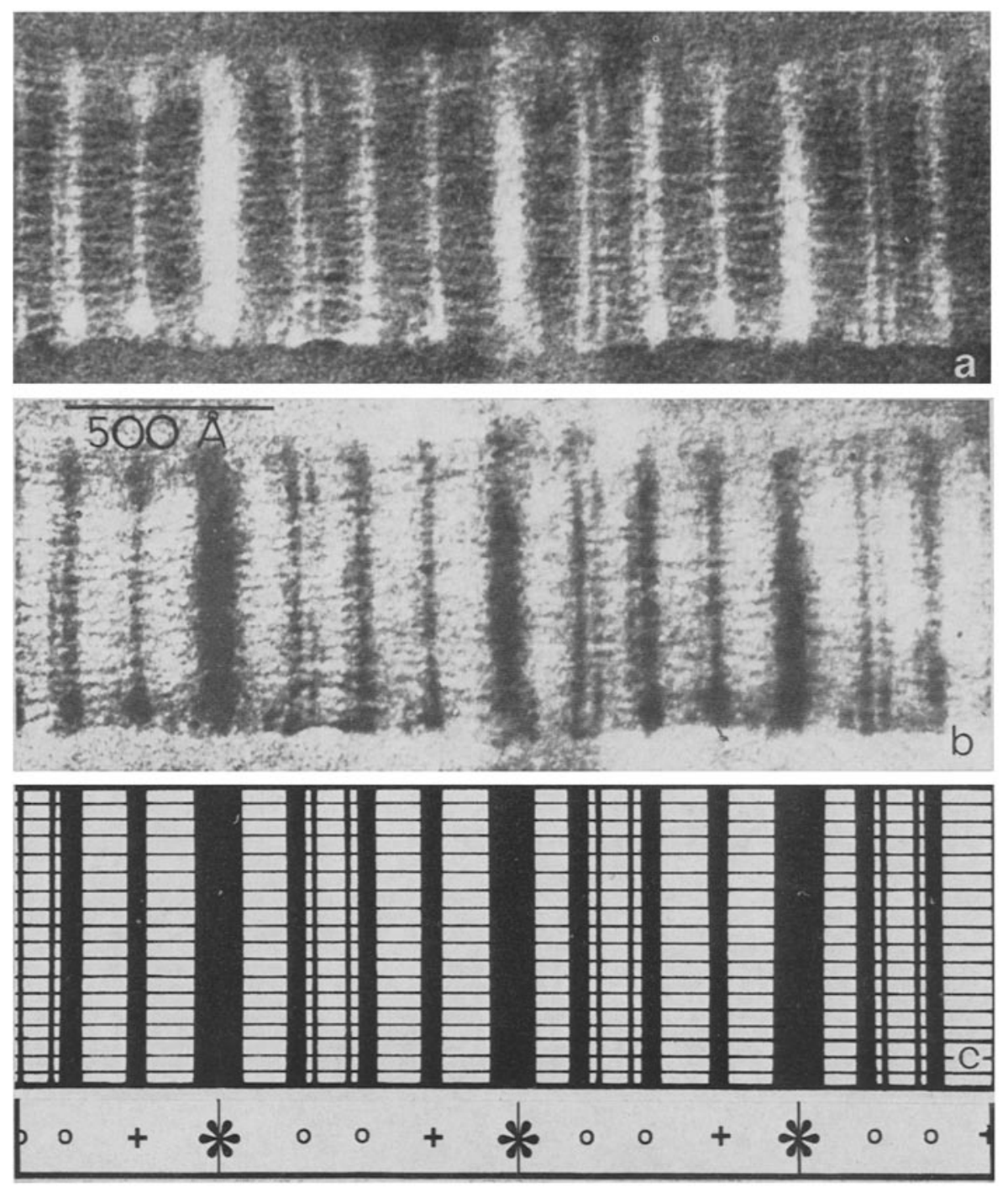

Abb. 3: Feinstruktureller Aufbau der gestreckten Trichocyste von Oxyrrbis marina. a Längsverlaufende Filamente mit einem Durchmesser von $10 \AA$ A inserieren in den hellen Banden, die teilweise aus globulären Elementen aufgebaut zu sein scheinen $(1 \%$ UA; $500000: 1) . b$ Die phototechnische Kontrastumkehr von Abb. $a$ gibt die natïrlichen Kontrastverhältnisse wieder. $c$ In einer Schemazeichnung sind die wesentlichen Strukruren des Schaftes zusammengefaßt

tronendurchlässiger geworden sind, ein Phänomen, das an Paramecium-Trichocysten of beobachtet werden kann. Bei den Tridhocysten von Oxyrrbis läßt sich jedoch durch Schrägbeschattung beweisen, daß an den entsprechenden Stellen verstärkt Material vorliegt, das sich durch intensivere Schattenwirkung hervorhebt (Dodge \& CRAWFORD 1971a). Im negativ kontrastierten Präparat wirkt sich eine solche Material- 
verdichtung natürlich durch eine hellere Region aus. Nach Auswertung einer größeren Anzahl von Bildern muß allerdings einschränkend bemerkt werden, daß die Hauptbanden wahrscheinlich infolge des Eintrocknens und des damit verbundenen Kollabierens des Schaftes etwas breiter erscheinen, als sie in vivo vorliegen.

Neben der regelmäßigen Untergliederung der Perioden erkennt man nun auch schon dünne, längs ausgerichtete Filamente, die in einer starken Vergrößerung deutlicher sichtbar werden (Abb. 3). Mit einem Durchmesser von $10 \AA$ verlaufen sie parallel zur Längsachse und strahlen in die im Negativkontrast hell erscheinenden Banden ein. Teilweise scheinen die Unterbanden, die wegen der geringen Masse nicht so stark kontrastiert sind, aus globulären Elementen zu bestehen, in denen die Fäden inserieren. Eine exakte Analyse dieser Bereiche ist aber wegen der durch die Präparatdicke bedingten Begrenzung des Auflösungsvermögens nicht möglich. In einer Schemazeichnung wird daher nur die Anordnung der unterschiedlich aufgebauten Banden verdeutlicht, die mit verschiedenen Symbolen gekennzeichnet sind (Abb. 3 c). Eine phototechnische Kontrastumkehr des negativkontrastierten Bildes soll eine Erleichterung für das Verständnis des Schemas darstellen und zugleich eine Dokumentation der normalen Kontrastverhältnisse bedeuten (Abb. $3 \mathrm{~b}$ ).

\section{Gebemmte Trichocysten}

In den Suspensionspräparaten können neben den oben beschriebenen ruhenden und gestreckten Trichocysten Stadien auftreten, die Hinweise dafür liefern, nach welchem Modus der Ubergang von der Ruheform zum gestreckten Zustand vonstatten geht. In den Abbildungen 4 und 5 sind solche Übergangsformen nach dem Ordnungsgrad der dünnen, den Schaft der gestreckten Trichocyste aufbauenden Filamente zusammengestellt. Wenn auch diese Zusammenstellung nach plausibel erscheinenden Gesichtspunkten erfolgte, kann sie nicht den Anspruch erheben, die chronologische Erfassung einzelner Phasen des Streckungsprozesses widerzuspiegeln. Denn zum einen wurde die Streckung nicht gezielt zu definierten Zeitpunkten gehemmt und zum anderen ist unbekannt, auf Grund welcher Einflüsse die Hemmstadien entstanden.

Die ersten beobachteten Veränderungen der ruhenden Trichocyste (Abb. 4 a) bestehen darin, daß sich die Kappenhülle (Abb. 4 b, großer Pfeil) rom Schaft ablöst, wobei gleichzeitig die Spitzeninnenstruktur freigelegt wird (Abb, $4 \mathrm{~b}$, Pfeilspitze). Aus dem Schaft treten dünne Fäden aus (Abb. 4 b, kleine Pfeile), die dimensionsmäßig mit den bei den ausgeschleuderten Trichocysten nachgewiesenen Filamenten identisch sind (vgl. Abb. 3). Das nächste Stadium ist dadurch gekennzeichnet, daß sich die Kappe vom Schaft weitgehend abgesondert hat (Abb. $4 \mathrm{c}$, Pfeil) und die fädigen

Abb. 4: Zusammenstellung gehemmter Trichocysten von Oxyrbis marina. a Die intakte, rubende Trichocyste ist aus Schaft (Sch) und Spitze (Sp) aufgebaut. $b$ Trichocyste, bei der sich die Spitzenkappe abgehoben hat (großer Pfeil). Aus dem Schafteil treten fädige Strukturen aus (kleine Pfeile). $c$ Nach yölliger Loslösung der Kappe (Pfeil) vergrößert sich das austretende Filamentbüschel. $d$ Ein Stadium, bei dem lange, im lockeren Verband stehende Fäden die Schaftülle verlassen haben (1\% PWS; $a-c: 55000: 1, d: 37000: 1)$ ( $a, c$ und $d$ vgl. HAUSMANN \& STOCXEM 1973) 

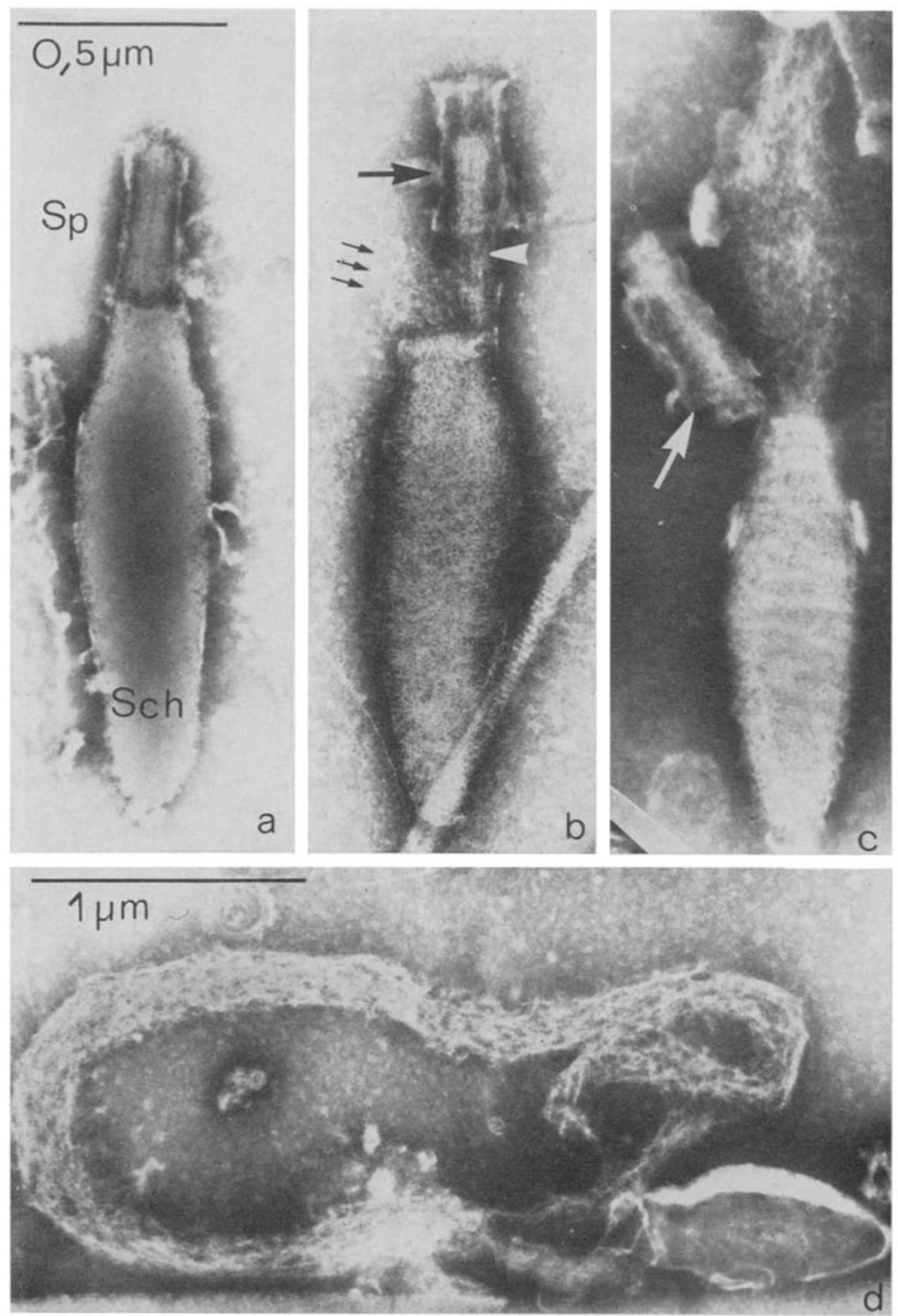

Abb. 4 
Strukturen büschelartig den Schaft verlassen. Im weiteren Verlauf verlängert sich das Filamentbuischel um ein Vielfaches des ruhenden Trichocystenschaftes (Abb. $4 \mathrm{~d}$ ). Die Fäden stehen im lodkeren Verband, bilden in dieser Abbildung jedoch keine Struktur höherer Ordnung aus. In anderen Präparaten können Stadien auftreten, bei denen die Fäden teilweise zu dem periodischen Muster der gestreckten Trichocyste aggregiert sind. Abbildung 5 a zeigt eine solche Trichocyste. Neben Bereichen, in denen das fertige Strukturmuster der gestreckten Form ausgebildet ist (Abb. $5 a, * *$ ), treten einerseits Areale auf, in denen das fädige Material noch völlig ungeordnet vorliegt (Abb. 5 a, *), andererseits Abschnitte, die bereits eine gewisse Periodizität im Filamentverband erkennen lassen (Abb. 5 a, Pfeilspitzen).

Der für den Vorgang der Streckung interessante Bereich ist natürlich die Region, in der sich aus dem Material der Ruheform der Schaft des ausgeschleuderten Zustandes bildet. An Hand von Präparaten, in denen das Gebiet der Materialtransformation von der ruhenden zur gestreckten Spindeltrichocyste gut sichtbar ist, kann gezeigt werden, daß der eine Zustand direkt in den anderen übergeht (Abb. 5 b,*). Es konnten keine Trichocysten beobachtet werden, die an der betreffenden Stelle Ordnungszustände aufwiesen, wie sie in Abbildung 5 a innerhalb eines bereits weitgehend gestreckten Schaftes dargestellt sind. In diesem Sinne sind die vorab beschriebenen Beobachtungen an Hemmstadien (Abb. 4 a-d und Abb. 5 a) als Artefakte anzusehen, die allerdings Anhaltspunkte für die Funktionsweise der Trichocysten abgeben (vgl. auch Diskussion). In diesem Zusammenhang ist auch der Befund interessant, daß Trichocysten auftreten, in denen innerhalb der Schafthülle der Ruheform neben einem bereits ausgeschleuderten Schaft mehrere Fragmente liegen, die das ausdifferenzierte Muster der 680 Â-Periode besitzen (Abb. $5 \mathrm{c}$, Pfeile). Auch hier fehlen Übergänge zwischen den beiden Materialzuständen, beispielsweise in Form von unterschiedlich breiten Periodenabständen.

Schließlich sind Stadien zu finden, die belegen, daß der Ausschleuderungsvorgang der Trichocyste ein kontinuierlicher Prozeß ist, währenddessen die Schatthille nach und nach entleert wird (Abb. $5 \mathrm{~d}$ und e), bis nur noch die leere Hülle vorliegt (Abb. 5 f). Wenn Schafthülle (Abb. 5 f, Pfeil) und Spitzenkappe (Abb. 5 f, Pfeilspitze) vereinigt bleiben, erfolgt die Abgabe des Materials durch eine Offnung im obersten Teil der Kappe. Solche Stadien werden jedoch selten gefunden, so daß sie entweder als Sonderform oder aber als Artefakt anzusehen sind.

Abb. 5: Zusammenstellung gehemmter Trichocysten yon Oxyrrbis marina. a Neben Bereichen, in denen die ausgetretenen Filamente zu einer geordneten, periodischen Struktur aggregieren $(* *)$, gibt es Areale, die völlig ungeordnet erscheinen (*), und solche, die bereits eine gewisse Periodizität des Materials erkennen lassen (Pfeilspitzen). $b$ In einer Ausschnittvergrößerung der Stelle, an der das Trichocystenmaterial die Schafthüle verläßt, wird deutlich, daß der gestreckte T'richocystenschaft übergangslos aus dem fädig-granulären Material der Ruheform entsteht ${ }^{*}$. Der entleerte Teil der Schafthüle ist transparent. $c$ Teilweise liegen vor der Austrittsoffnung innerhalb der Schafthülle Trichocystenfragmente, die die charakteristische Querstreifung der gestreckten Trichocyste besitzen (Pfeile). $d-f$ Nach und nach entleert sich die Trichocyste $(d, e)$, bis schließlich nur noch die transparente Schafthille vorliegt $(f)$. Wenn Spitzenkappe (Pfeilspitze) und Schafthülle (Pfeil) verbunden bleiben $(f)$, tritt das Material durch eine Offnung in der Kappe aus (1\% PWS; $a-c: 63000: 1, d-f: 50000: 1$ ) (a und $b:$ vgl. HAusMANN \& STOCKEM 1973) 

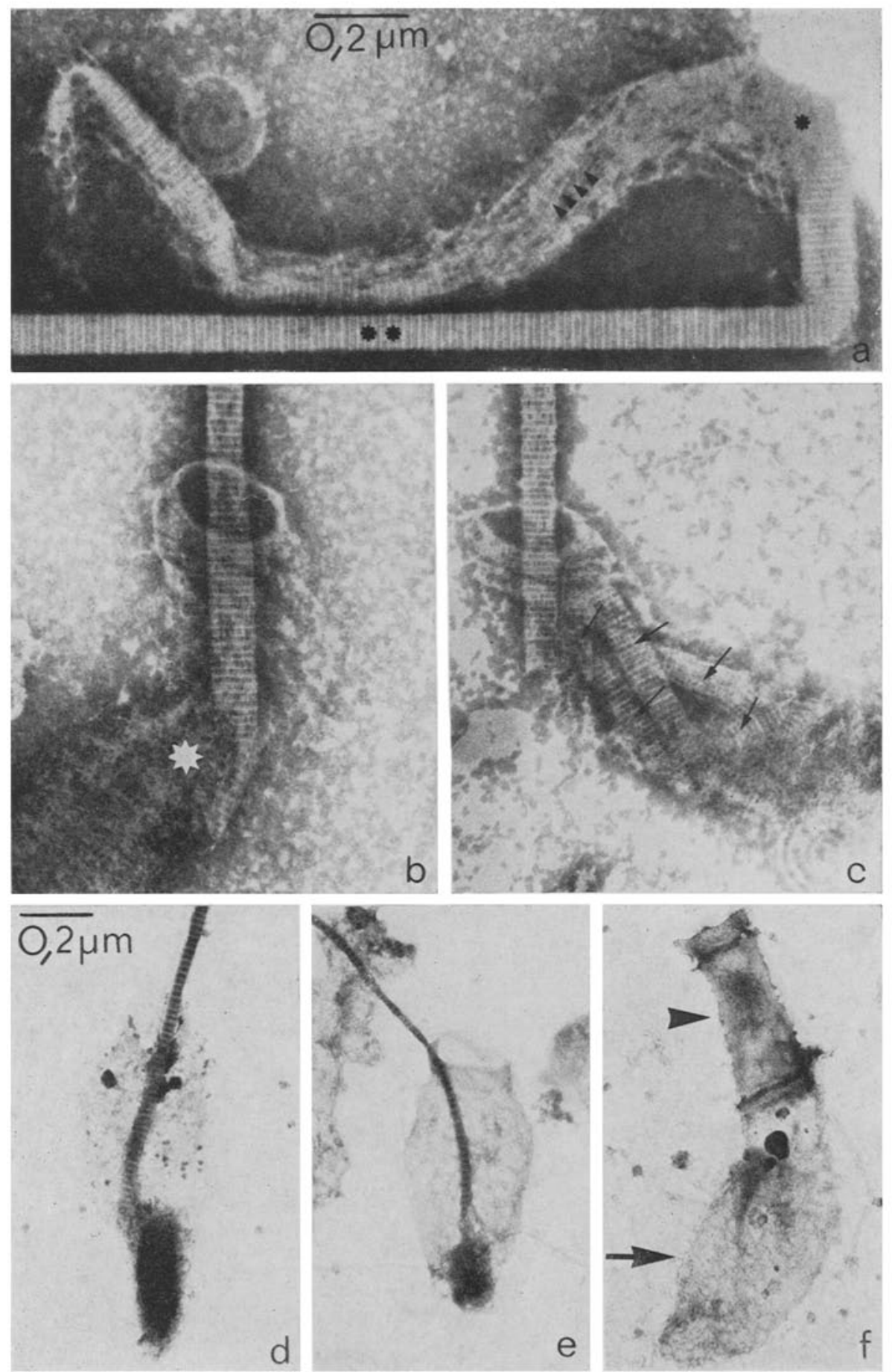


\section{Pleuronema marinum}

Pleuronema marinum ist, wie bereits lichtmikroskopisch erkennbar, mit Spindeltrichocysten ausgestattet, die keine besonders strukturierte Spitze besitzen. Wie sich zeigte, lassen sich die Ruhestadien am besten im Schnittpräparat untersuchen (Abb. 6), wohingegen bei den gestreckten (Abb. 8) und den in der Ausschleuderung gehemmten Formen (Abb. 7) durch die Suspensionstechnik die meisten Informationen erzielt werden können. Im folgenden werden ausgehend von den Ruheformen über gehemmte Stadien die Strukturverhältnisse der gestreckten Trichocysten dargelegt und zugleich, soweit möglich, Parallelen und Übereinstimmungen mit den Trichocysten von Oxyrrhis marina aufgezeigt.

\section{Rubende und gebemmte Trichocysten}

Ihrer Funktionsweise gemäß (blitzschnelles Austreten aus dem Zellkörper) liegen die ruhenden Trichocysten unmittelbar unter der Pellicula zwischen den Mitochondrien (Abb. 6 a, Pfeile), die bei Ciliaten besonders zahlreich in corticalen Plasma der Zelle angeordnet sind (Abb. 6 a, M). Die Trichocysten sind mit einer durchschnittlichen Größe von 0,5-1 $\mu \mathrm{m}$ rundlich-ovale Körper, die von einer Elementarmembran umgeben werden (Abb. 6 b, Pfeile). Die bei schwacher Vergrößerung andeutungsweise erkennbare Parakristallinität des Materials (Abb. $6 \mathrm{~b}$ ) tritt bei einer stärkeren Vergrößerung deutlich in Erscheinung (Abb. $6 \mathrm{c}$ ). Dunkle und hellere Banden wechseln periodisch in Abständen von 65-80 $\AA$ und bilden dadurch das parakristalline Strukturgefüge, das für die Ruheform vieler Trichocysten charakteristisch ist (vgl. auch den entsprechenden Abschnitt über ruhende Trichocysten bei Oxyrrbis marina, Abb. 1 d).

Der parakristalline Aufbau der Ruheformen kann nur nach einer Osmium-ChromFixierung dargestellt werden. Eine Fixation mit Glutaraldehyd zeigt dahingegen Trichocysten, die sowohl volumenmäßig als auch in feinstruktureller Hinsicht von den mit Osmium-Chrom-fixierten Organellen abweichen (Abb. $6 \mathrm{~d}$ ). Das Material ist gequollen und lockerer (Abb. 6 d, *). Es herrscht ein granulärex, ungeordneter Strukturaspekt vor. Neben den noch in der Zelle verbliebenen Trichocysten können bereits Stadien auftreten, die mit der Ausschleuderung begonnen haben (Abb. $6 \mathrm{~d}$, **) In diesen Fällen hat sich die Membran nach außen geöffnet (Abb. 6 d, Pfeile), und das

Abb. 6: Ruhende und gehemmte Trichocysten von Pleuronema marinum. a Die ruhenden Trichocysten liegen dicht unter der Pellicula (Pfeile) zwischen zahlreichen Mitochondrien (M). $\mathrm{C}=$ Cilie $(3 \%$ Osmium; $25000: 1)$. $b$ In einer stärkeren Vergrößerung wird die Membran deutlich, die die Trichocyste umgibt (Pfeile) (3\% Osmium; 50000:1). c In einer starken VergröBerung tritt die Parakristallinität des Materials in- Erscheinung ( $3 \%$ Osmium; $175000: 1)$. $d$ Nach einer langsam wirkenden Fixierung ist die Tridhocyste gequollen $\left({ }^{*}\right)$. Daneben gibt es Formen, die mit der Ausscheidung begonnen haben (**). Das Material tritt durch eine Offnung in der Membran aus (Pfeile) und wird lockerer (o) $5 \%$ Glutaraldehyd; $50000: 1)$. e In gänzlich aus dem Zellkörper ausgetretenen, jedoch nicht völlig gestreckten Trichocysten erkennt man fädige, teilweise miteinander verknüpte Elemente $50 \%$ Glutaraldehyd; $100000: 1$ ) 

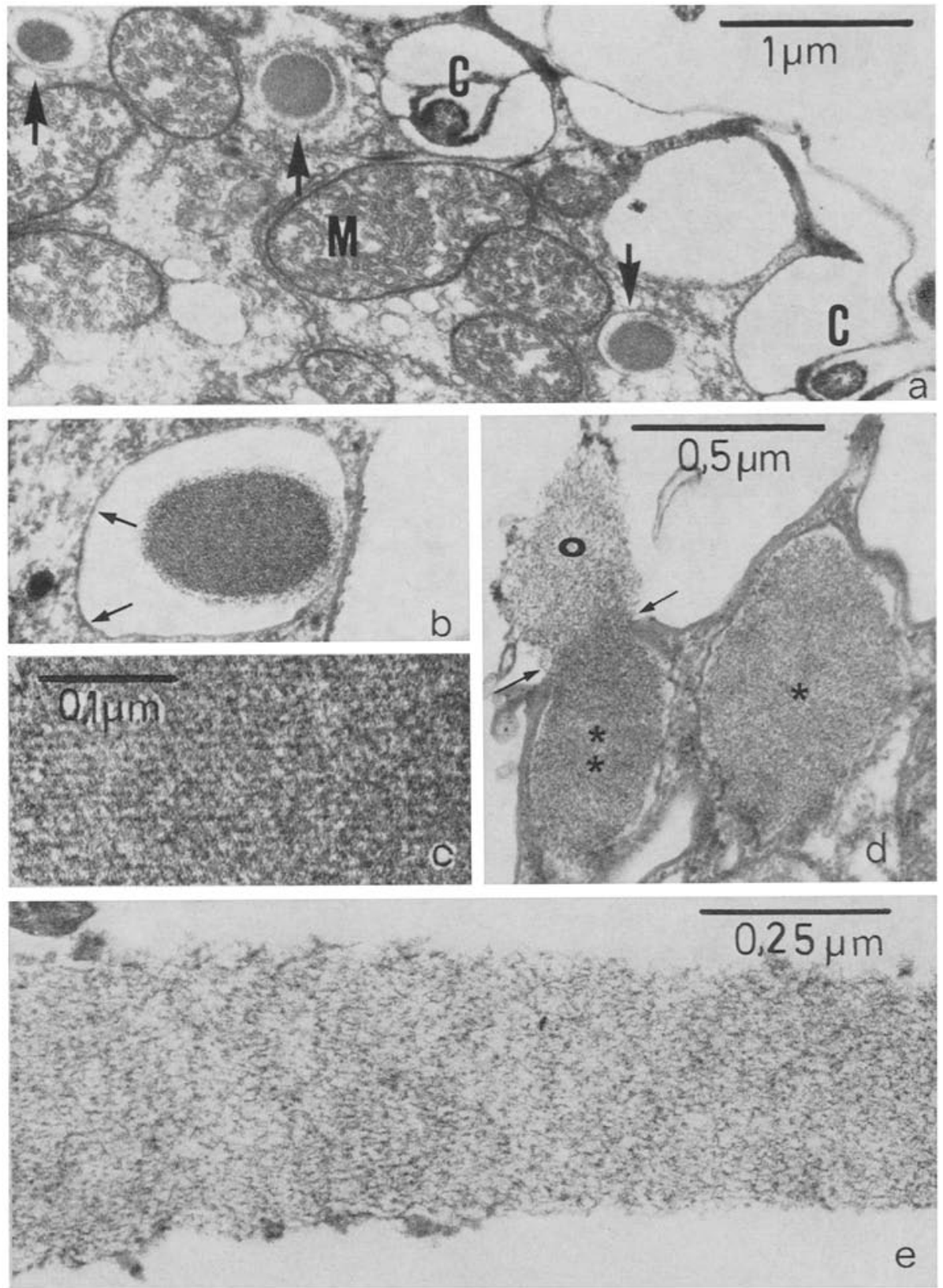
Trichocystenmaterial tritt aus der Zelle aus, wobei es sich weiter auflockert und einen fädig-granulären Strukturaspekt annimmt (Abb. 6d, o). Diese Stadien weisen sehr große morphologische Ahnlichkeit mit den Glutaraldehyd-fixierten Mucocysten auf (vgl. Hausmann 1973a, b), ein Befund, der die Verwandtschaft zwischen Spindeltrichocysten und Mucocysten noch enger erscheinen läßt. Die Tatsache, daß solche $\mathrm{Zu}-$ standsformen nur nach einer Glutaraldehyd-Fixierung auftreten, zeigt, daß die ruhenden, parakristallinen Trichocysten in ihrer Konsistenz labile Systeme darstellen, die durch ein langsam wirkendes Fixanz, wie zum Beispiel den Glutaraldehyd, nicht in der ruhenden Form erhalten bleiben, wie es nach einer schneller wirkenden OsmiumChrom-Fixierung eher der Fall ist. Die Glutaraldehyd-Fixation erfolgt sogar in einzelnen Fällen so langsam, daß die Trichocysten den Zelleib noch während der Fixierung verlassen. Diese länglich gestreckten Formen bestehen aus locker angeordneten, 15-20 ̊ dicken Filamenten, die eine Vorzugsrichtung parallel zur Längsachse einnehmen (Abb. 6e). Die Filamente sind anscheinend regellos untereinander verknüpt und ergeben somit ein ungeordnetes Netzwerk.

Da sich aus den Schnittbildern keine anderen Informationen uber gehemmte Trichocysten herleiten lassen, wurde zur weiteren Untersuchung an Suspensionspräparaten das Negativ-staining-Verfahren angewandt.

In Abbildung 7 sind unterschiedliche Ausschleuderungsstadien zusammengestellt. Der ruhende Teil der Trichocyste ist deutlich vom gestreckten Schaft zu unterscheiden (Abb. $7 \mathrm{a}, \mathrm{r} \mathrm{Tr}=$ ruhende Trichocyste, $\mathrm{g} \mathrm{Tr}=$ gestreckte 'Trichocyste). Im Zusammenhang mit den Schnittbildern ist der ruhende Bereich als der von einer Membran umgebene Teil anzusehen, der normalerweise in der Zelle verbleibt (vgl. Abb. 7 a, $r$ Tr mit Abb. $6 \mathrm{~d}, \%$. Die Offnung in der Membran, die bereits im Schnitt gezeigt wurde (Abb. 6d, Pfeile), tritt im negativkontrastierten Suspensionspräparat als heller Streifen in Erscheinung (Abb. $7 a-c$, Pfeile). Im Gegensatz zur Schnittuntersuchung (Abb. 6 e) ist die Struktur des gestreckten Schaftes durch eine gleichförmige Querstreifung charakterisiert (Abb. 7 a-c, Pfeilspitzen). Die drei Stadien zeigen im wesentlichen unterschiedlich weit gestreckte Schäfte ohne andersartige Strukturen.

$\mathrm{Da}$ die Trichocysten von Pleuronema marinum dimensionsmäßig günstige $\mathrm{Ob}-$ jekte sind, die in der Übersicht gut total dargestellt werden können (im Gegensatz zu Oxyrrbis, bei dem die gestreckte Trichocyste für eine Ubersicht zu lang und zu dünn ist), wurden bewußt solche Stadien ausgewählt, die am ehesten als eine Dokumentation des natürlich ablaufenden Ausschleuderungsvorganges anzusehen sind: Eine kontinuierliche, übergangslose Streckung der ruhenden Trichocyste zu der periodisch quergestreiften Form. Die Abbildungen 7 a bis c sollen eine direkte Vorstellung dieses Vorganges vermitteln.

In diesem Zusammenhang muß erwähnt werden, daß auch bei den PleuronemaTrichocysten solche Hemmformen beobachtet werden konnten, wie sie am Beispiel der Oxyrrbis-Trichocysten gezeigt wurden (vgl. Abb. 4 und 5). Da sich die Befunde in den wesentlichen Punkten gleichen (vgl. den Abschnitt ïber gehemmte Trichocysten bei Oxyrrbis marina), soll im Fall von Pleuronema auf einen bildlichen Beleg dieser Stadien verzichtet werden. 

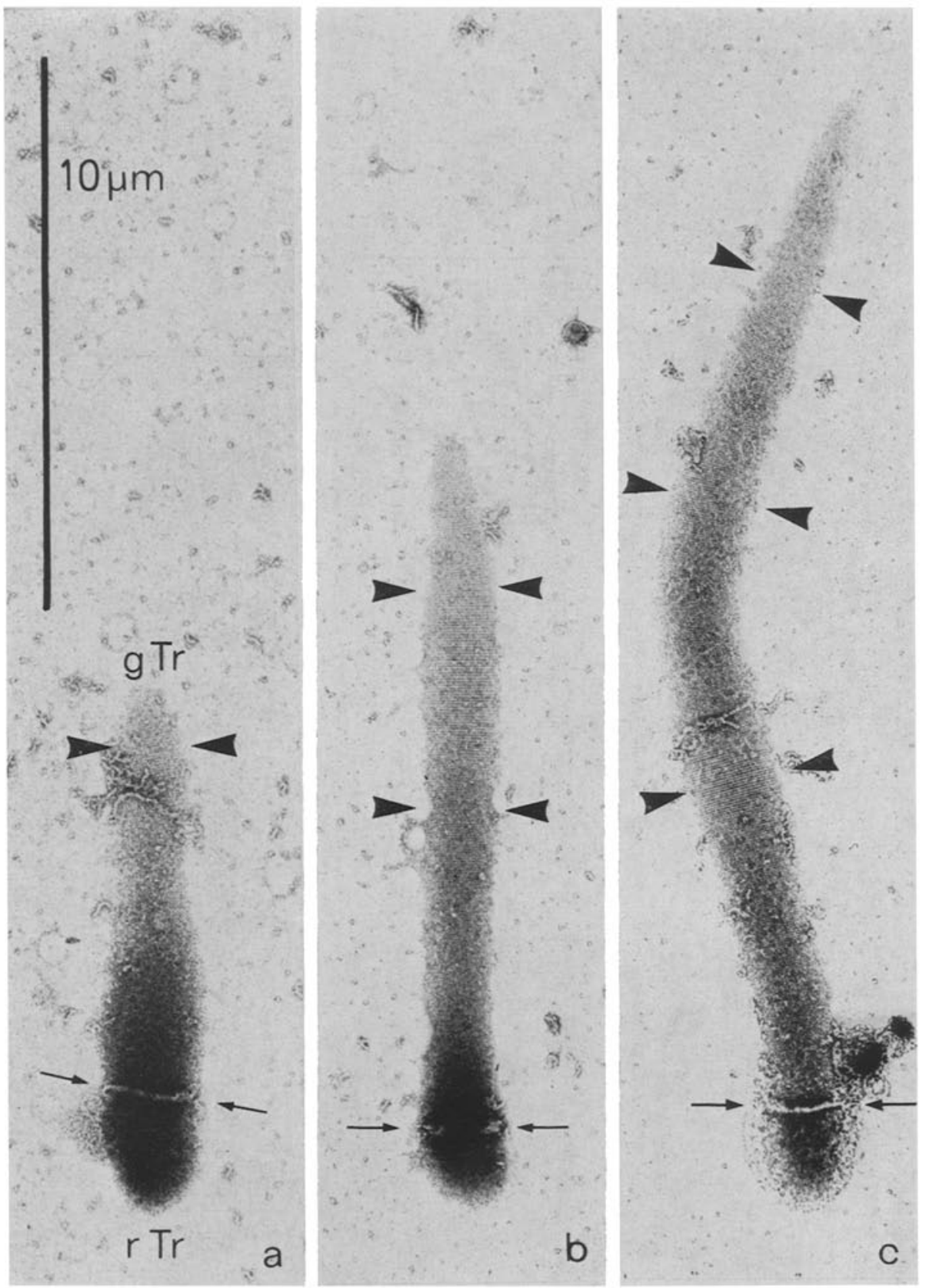

Abb. 7: Unterschiedliche Ausschleuderungsstadien der Trichocysten von Pleuronema marinum. $a-c$ Der ruhende Teil der Trichocyste ( $\mathrm{r} T \mathrm{r}$ ) besitzt keine erkennbare Innenstruktur, während der gestreckte Schaft ( $\mathrm{g}$ Tr) periodisch quergestreift ist (Pfeilspitzen). Nähere Beschreibung siehe Text (1\% PWS; $7300: 1)$ 


\section{Gestreckte Trichocysten}

Wie aus den Suspensionspräparaten gehemmter Trichocysten hervorgeht, ist das Charakteristikum des gestreckten Schaftes eine periodische Querstreifung (Abb. 7 a-c, Pfeilspitzen). Der Periodenabstand dieser Streifung bleibt in gänzlich gestreckten Trichocysten nach unterschiedlichen Behandlungen der Suspensionen gleich, nämlich $560 \AA$ A (Abb. 8 a - c, Pfeilspitzen). Die Breite des Schaftes variiert jedoch erheblich: Nach Schrägbeschattung ca. 1,2 $\mu \mathrm{m}$ breit (Abb. $8 \mathrm{a}$ ); nach UA-Kontrastierung $\mathrm{ca}$. $0,7 \mu \mathrm{m}$ breit (Abb. $8 \mathrm{~b}$ ); nach PWS-Kontrastierung ca. 1,7 $\mu \mathrm{m}$ breit (Abb. $8 \mathrm{c}$ ). Vergleichbare Erscheinungen wurden auch bei den Oxyrrbis-Trichocysten festgestellt (vgl. Abb. 2 b-e). Dort wie hier müssen diese Dimensionsschwankungen in unterschiedlichen Reaktionen des Materials auf die Kontrastierungsart gesehen werden. Es kann angenommen werden, daß die UA-Kontrastierung (Abb. 8 b) durch eine stärker fixierende Wirkung die Strukturen am naturgetreuesten. wiedergibt (vgl. auch Abb. $2 \mathrm{~b}$ und e). Der Schaft erscheint kompakt und lediglich in den Randregionen etwas lichter. Nach der PWS-Kontrastierung (Abb. 8c) ist das Material des Schaftes elektronendurchlässig, da es wahrscheinlich zu einer dünnen Struktur gespreitet ist.

Eine höhere Vergrößerung der gestreckten Trichocyste zeigt nach UA- (Abb. $8 \mathrm{~d}$ ) und PWS-Kontrastierung (Abb. 8 e) unterschiedliche Strukturen. In beiden Fällen ist jedoch zu erkennen, daß längsverlaufende Fäden die wesentlichen Bauelemente des gestreckten Schaftes sind, die nach der PWS-Kontrastierung an einigen Stellen miteinander verknüpft zu sein scheinen.

Bei den vorliegenden Bildern (Abb. $8 \mathrm{~d}$ und e) läßt es sidh nicht entscheiden, welche Darstellung des Trichocystenschaftes den natürlichen Gegebenheiten entspricht. Ohne im Detail auf die Abweichungen im morphologischen Bild einzugehen, sei auf die Problematik hingewiesen, bei der Beschreibung feinstruktureller Einzelheiten nur die mit Hilfe e i n e Kontrastierungsart gewonnenen Resultate heranzuziehen (vgl. den Abschnitt über gestreckte Trichocysten bei Oxyrrbis marina; $\mathrm{Abb} .2 \mathrm{~d}$ und e; siehe auch Hausmann \& STOCKem 1973).

Die vorliegenden Befunde an ruhenden, gehemmten und gestreckten Trichocysten von Oxyrrhis marina sowie Pleuronema marinum weisen im Hinblick auf Funktionsmechanismus und Feinstruktur auffallende Parallelen zu den Ergebnissen der Untersuchungen an Spindeltrichocysten von Paramecium caudatum auf (vgl. HausmanN et al. $1972 \mathrm{a}, \mathrm{b}$ ). Die Besprechung dieser Homologieerscheinungen soll ein wesentlicher Punkt des folgenden Kapitels sein.

\section{DISKUSSION}

Da in Bau und Funktionsweise zwischen den Oxyrrbis- und Pleuronema-Trichocysten einerseits und den Paramecium-Trichocysten andererseits offenkundige Parallelen vorliegen, sollen, bevor diese Übereinstimmungen näher diskutiert werden, die wesentlichen Fakten der Paramecium-Trichocyste in stark geraffter Form dargelegt werden (vgl. Hausmann et al. $1972 \mathrm{a}, \mathrm{b}$ ). 

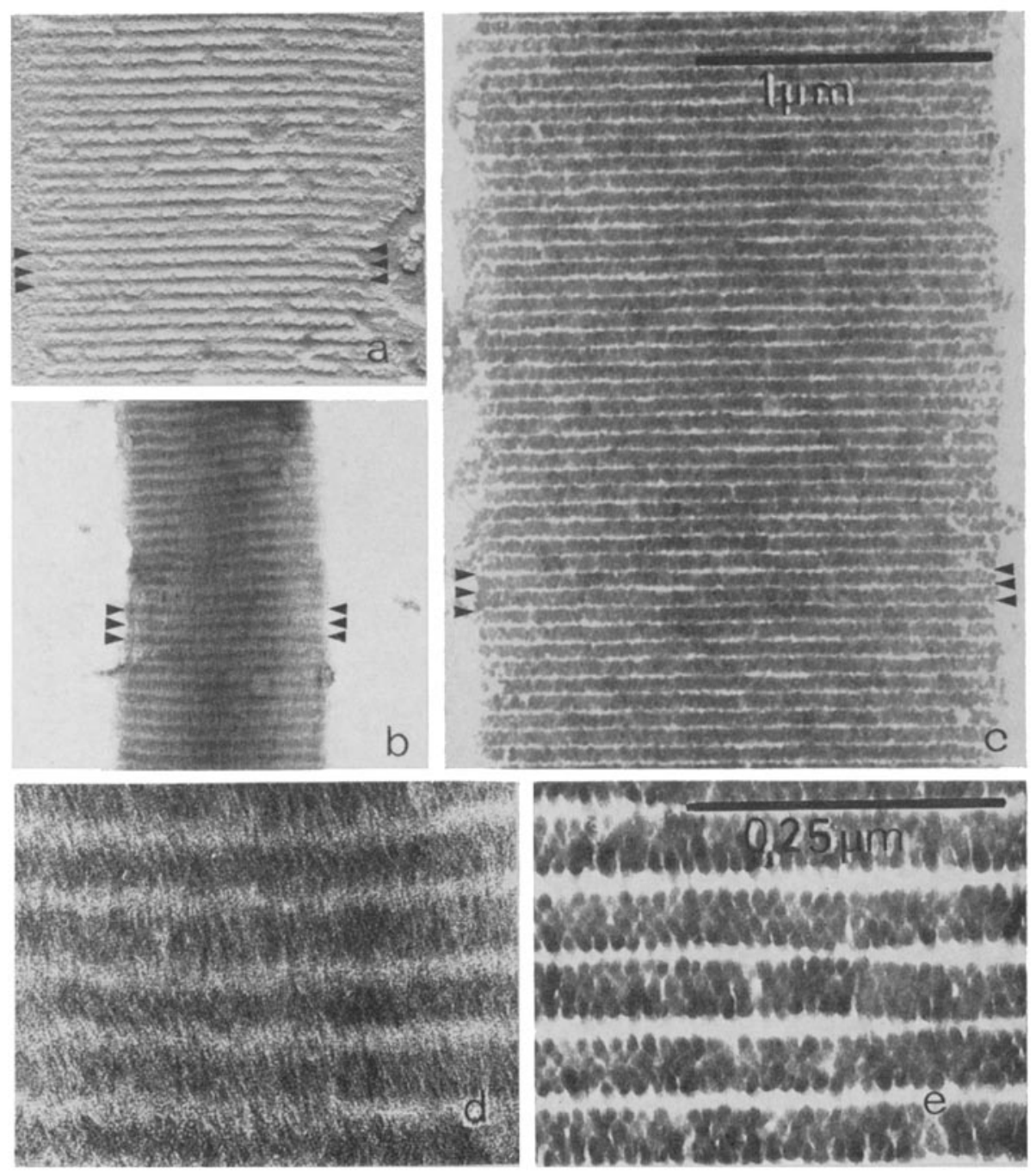

Abb. 8: Gestreckte Trichocysten von Pleuronema marinum, $a-c$ Bei gleichbleibendem Periodenabstand (Pfeilspitzen) erscheint der gestreckte Trichocystenschaft nach verschiedenen Kontrastierungsarten unterschiedlich breit $(a=$ Schrägbeschattung; $b=1 \%$ UA; $c=1 \%$ PWS; $35000: 1)$. $d$ In einer höheren Vergrößerung werden die Filamente sichtbar, die den gestreck-ten Trichocystenschaft aufbauen (1\% UA; $150000: 1)$. $e$ Wie Abbildung $d$, jedoch nach PWSKontrastierung. Nähere Beschreibung siehe Text $(1 \%$ PWS; $150000: 1) d$ und $e$ vgl. HausMANN \& STOCKEM 1973)

In der ruhenden Paramecium-Trichocyste sind alle gestaltlichen Elemente der ausgeschleuderten Trichocyste in Form eines parakristallin angeordneten Strukturproteins vorgegeben. Die plötzliche Streckung der parakristallinen Struktur zu einem zweiten, ebenfalls parakristallinen Zustand muß auf Grund von Dialyse- und Hemm- 


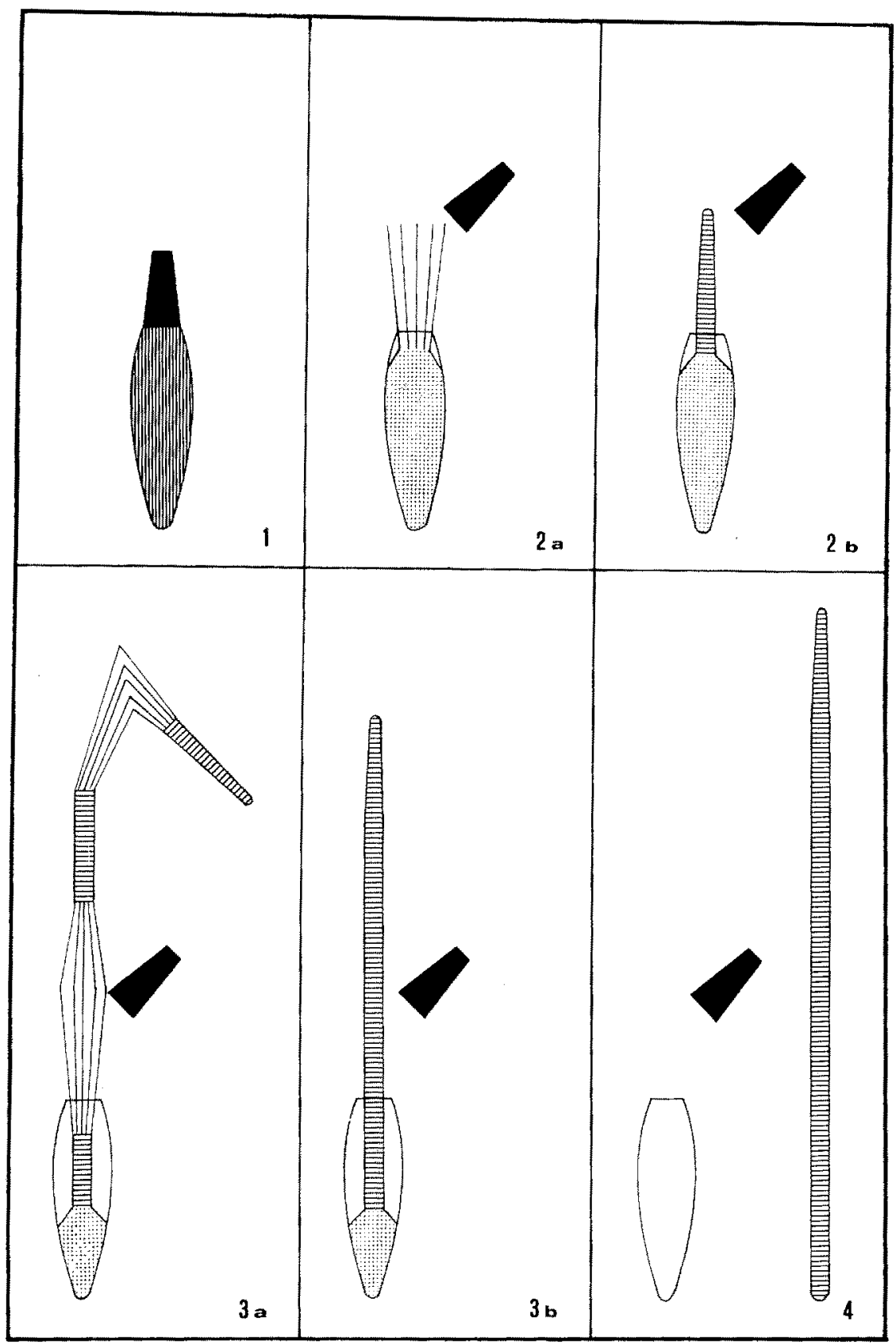

Abb. 9: Schematische Zusammenstellung verschiedener Trichocystenstadien von Oxyrrbis marina. Nähere Beschreibung siehe Diskussion (vgl. Hausmann \& Stockem 1973) 


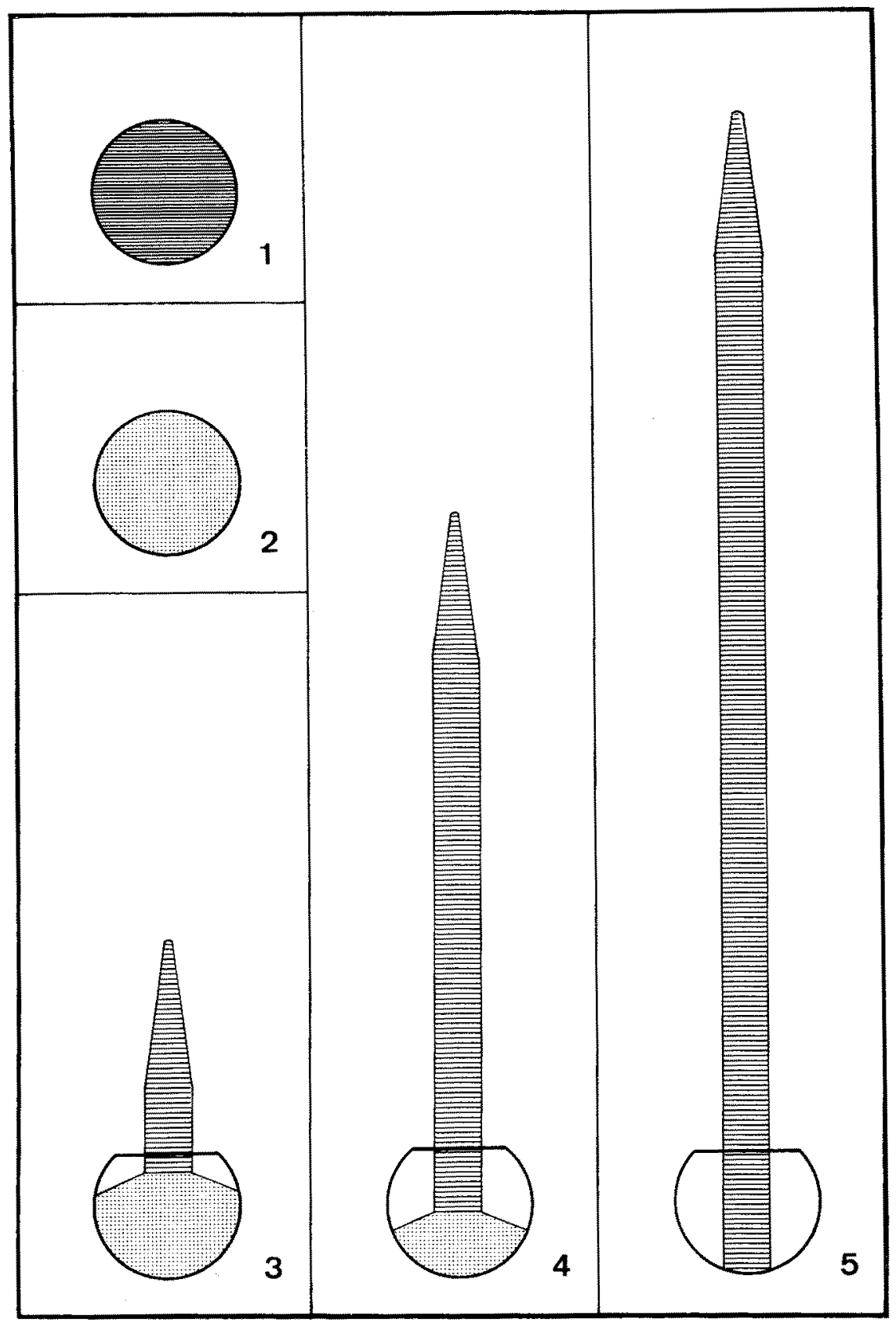

Abb. 10: Schematische Zusammenstellung verschiedener Trichocystenstadien von Pleuronema marinum. Nähere Beschreibung siehe Diskussion 
versuchen als eine spontane Umordnung des hochgeordneten Eiweißsystems angesehen und der Umordnungsvorgang als die Entfaltung einer präformierten Struktur interpretiert werden.

Das Charakteristikum der ruhenden Oxyrrhis- und Pleuronema-Trichocyste ist ebenfalls eine parakristalline Anordnung des Schaftmaterials. Allerdings wird bei Oxyrrbis ausschließlich eine Längsstreifung beobachtet (Abb. $1 \mathrm{~d}$; DODGE \& CRAWFORD 1971a), während bei Pleuronema und Paramecium eine Querstreifung ïberwiegt (Abb. 6b und c; HaUSMANN et al. 1972b). Ob die andersartige Ausrichtung der Streifung bei den Ruheformen der Oxyrrbis-Trichocysten lediglich eine belanglose Variation der Strukturanordnung bedeutet, oder ob diese auffällige Anderung des Musters als ein Hinweis für besondere Eigenschaften der ruhenden Trichocyste zu bewerten ist, kann auf Grund der vorliegenden Untersuchung nicht entschieden werden.

Die Schäfte der gestreckten Spindeltrichocysten von Oxyrrbis, Pleuronema und Paramecium weisen eine Querstreifung auf, die aus einer periodischen Abfolge von elektronendichten und weniger elektronendichten Banden resultiert. Im feinstrukturellen Bereich treten jedoch unterschiedliche Strukturmuster auf, was unter Umständen auf die unterschiedlichen Konfigurationen der Struktureiweiße zurückgeführt werden kann (vgl. hierzu Masser \& BeN-Shaul 1971, Steers et al. 1969). Als kieinste nachweisbare Strukturkomponenten bilden bei den drei Trichocystentypen zum Schaft längsverlaufende Filamente mit einem Durchmesser von $10-15 \bar{A}$ ein höher geordnetes Muster aus, das bei Paramecium und mit Einschränkung auch bei Pleuronema komplizierter erscheint als bei Oxyrrbis.

Das an Oxyrrbis-Trichocysten beobachtete Muster erinnert an die Strukturverhältnisse des Kollagens (DICKERSON \& GeIs 1969, Schmrt 1968). Wenn auch die chemische Zusammensetzung des Kollagens nicht mit der der Oxyrrbis-Trichocysten gleichzusetzen ist (MESSER \& BEN-SHAur 1971), wäre es lohnend, die Darstellung der monomeren Komponenten durch Säurehydrolyse an isolierten Oxyrrbis-T'trichocysten zu erproben, ein Experiment, aus dem die Kenntnisse über die Gestalt und Länge des Kollagenmoleküls resultieren (SEIFTER \& GALLOp 1966).

Die Beobachtung, daß Trichocystenschäfte auftreten, bei denen die Fäden im lockeren, ungeordneten Verband vorliegen (Abb. 4), kann so gedeutet werden, daß das Material der ruhenden Trichocyste während des Übergangs vom ruhenden zum gestreckten Schaft kurzzeitig aufgelockert wird, um anschließend das Muster der gestreckten Trichocyste zu bilden, ein Vorgang, der in Bruchteilen von Sekunden vor sich geht. Es ist unbekannt, wie die Hemmstadien entstehen. Möglich ist, daß in der ruhenden Trichocyste reaktive chemische Gruppen bestehen, die während der Ausschleuderung abgesättigt werden. Die Hemmung bestünde dann in einer Blockade dieser Gruppen, die verhindert, daß das fädige Material zum Muster der gestreckten Trichocyste aggregiert. Andererseits kann die Hemmung darauf beruhen, daß eine während der Streckung der Trichocyste benötigte Substanz in ihrer Wirkungsweise gehindert wird und somit die Ausschleuderung zum Erliegen kommt.

$\mathrm{Da}$ die Morphologie ruhender und gestreckter Spindeltrichocysten von Oxyrrbis, Pleuronema sowie Paramecium in den wesentlichen Punkten übereinstimmen und darüber hinaus die Hemmstadien in allen drei Fällen durch gleiche Eigenheiten cha- 
rakterisiert sind, liegt der Schluß nahe, daß bei den drei Trichocysten derselbe Mechanismus für die Umordnung des Strukturproteins vorliegt, nämlich die Entfaltung eines in den ruhenden Trichocysten präformiert vorliegenden Strukturmusters.

Die Entfaltung und damit verbundene Streckung der Oxyrrbis-Trichocyste läuft demnach folgendermaßen $a b$ (Abb. 9, 1-4): Ausgehend von der ruhenden Trichocyste (vgl. Abb. 9, 1 mit Abb. 1 a und 4 a) erfolgt zuerst eine Loslösung der Spitzenkappe (vgl. Abb. 9, 2 mit Abb. 4 b). Der Austritt ungeordneter Filamente (vgl. Abb. 9, 2 a mit Abb. 4 b, c und d) muß als Artefakt angesehen werden. Das Material geht vielmehr direkt und übergangslos vom ruhenden in den gestreckten Zustand über (vgl. Abb. 9, 2 b mit Abb, 5 b). Die Entfaltung und Streckung des Trichocystenschaftes ist ein kontinuierlicher Vorgang (vgl. Abb. 9, $3 \mathrm{~b}$ mit $\mathrm{Abb} .5 \mathrm{~d}$ und e), der erst dann ein Ende findet, wenn sämtliches Material vom einen in den anderen Zustand übergegangen ist (vgl. Abb. 9, 4 mit Abb. 5f). Dieser Prozeß kann infolge der Präparation so verändert sein, daß Schäfte mit einer lokalen Aufhebung des hochgeordneten Periodenmusters zur Darstellung gelangen (vgl. Abb. 9, 3 a mit Abb. 5 a).

Ganz ähnlich verläuft die Ausschleuderung der Pleuronema-'Trichocyste (Abb, 10, 1-5): Der Ursprung der Trichocystenabgabe ist in der ruhenden, parakristallinen Trichocyste zu sehen (vgl. Abb. 10, 1 mit Abb. 6a-c), die sich über Zwischenstadien (vgl. Abb. 10, 2 mit Abb. $6 \mathrm{~d}^{*}$ ) kontinuierlich zu dem völlig ausgeschleuderten Schaf streckt (vgl. Abb. 10, 3-5 mit Abb. 7 a-c).

Der Nachweis, daß in der Streckung der Trichocysten von Oxyrrhis und Pleuronema ebenfalls wie bei den Paramecium-Trichocysten ein Entfaltungsvorgang präformierter Strukturen vorliegt, ist insofern erstaunlich, als einerseits zwischen den beiden Protisten Oxyrrhis und Paramecium eine beträchtliche Klutt hinsichtlich der systematischen Eingliederung besteht und andererseits die ökologischen Bedürfnisse der besprochenen Meerwasserorganismen im Vergleich zum Süßwasserciliat Paramecium sehr gegensätzlich erscheinen. Die Tatsache der offensichtlichen Ubereinstimmung in Morphologie und Ausschleuderungsmodus der Spindeltrichocysten gibt noch mehr als bisher Anlaß dazu, intensiv nach der weitgehend unklaren Funktion dieser Organelle zu suchen.

\section{ZUSAMMENFASSUNG}

1. Der Dinoflagellat Oxyrrbis marina und der Ciliat Pleuronema marinum wurden hinsichtlich der Feinstruktur und des Funktionsmodus ihrer Trichocysten untersucht.

2. Die ruhende Trichocyste von O. marina ist aus Schaft und Spitze aufgebaut. Während die Spitze eine tubuläre Innenstruktur aufweist, besitzt das Material des Schaftes eine längsorientierte Streifung von $80 \AA$ mit einer Unterperiode von 40 Å.

3. Die ruhende Trichocyste von $P$. marinum besitzt eine paralsristalline Struktur mit einer Periode von $65-80 \AA$.

4. Die gestreckte Trichocyste von $O$. marina ist durch eine Querstreifung mit einer Hauptperiode von $680 \AA$ mit Unterperioden von 160-170 Å gekennzeichnet. Es 
werden als kleinste Strukturkomponenten des Schaftes Filamente mit einem Durchmesser von $10 \AA$ nachgewiesen, die zur Trichocystenlängsachse parallel verlaufen.

5. Die gestreckte Trichocyste von P. marinum besitzt eine Querstreifung mit einer Periode von $560 \AA \bar{A}$. 10-15 $\AA$ A messende Filamente, die in der Hauptrichtung parallel zur Trichocystenlängsachse verlaufen, bilden ein geordnetes Netzwerk, das den Strukturen der gestreckten Paramecium-Trichocyste ähnlich ist.

6. An Hand gehemmter Trichocystenstadien von $O$. marina und P. marinum kann gezeigt werden, daß die Ausschleuderung der Trichocysten als Streckung zu verstehen ist, die durch den Ubergang eines parakristallinen Zustandes in einen anderen parakristallinen Zustand gedeutet werden muß.

7. Die Befunde der Oxyrrbis- und Pleuronema-Trichocysten werden mit den an Paramecium-Trichocysten erzielten Ergebnissen verglichen. Es zeigt sich, daß bei den drei Trichocysten gleichgeartete Verhältnisse insofern vorliegen, als auch in der Streckung der Oxyrrbis- und Pleuronema-Trichocysten ein Entfaltungsvorgang präformierter Strukturen gesehen werden muß.

\section{ZITIERTE LITERATUR}

ANDERSON, E., 1962. A cytological study of Chilomonas paramecium with particular reference to so-called trichocysts. J. Protozool. 9, 380-395.

BoucK, B. G. \& SwEENEY, B. M., 1966. The fine structure and ontogeny of trichocysts in marine dinoflagellates. Protoplasma 61, 205-223.

Chatton, E., 1914. Les cnidocystes du peridinien Polykrikos schwartzi Bütschli. Structure, fonctionement, ontogenese, homologies. Archs. Zool. exp. gén. 54, 157-194.

- \& Hovasse, R., 1944. Sur les premiers stades de la cnidogenese chez le peridinien Polykrikos schwartzi. C. r. hebd. Séanc. Acad. Sci., Paris 218, 60.

Dickerson, R. E. \& GeIs, I., 1969. The structure and action of proteins. Harper \& Row, New York, 40-43.

Dodge, J. D. \& Crawrord, R. M., 1968. Fine structure of the dinoflagellate Amphidinium carteri HulburT. Protistologica 4, 231-242.

- 1971a. Fine structure of the dinoflagellate Oxyrrbis marina. I. The general structure of the cell. Protistologica 7, 295-304.

- 1971b. Fine structure of the dinoflagellate Oxyrrbis marina. II. The flagellarsystem. Protistologica 7, 399-409.

Dragesco, J., 1952. Le flagelle Oxyrrbis marina: cytologie, trichocystes, position systematique. Bull. Microsc. appl. 2, 148-157.

- \& Hollande, A., 1965. Sur la presence des trichocystes fibreux chez les peridiniens; leur homologie avec les trichocystes fusiformes des cilies. C. r. hebd. Séanc. Acad. Sci., Paris 260, 2073-2076.

GrELL, K. G., 1968. Protozoologie. Springer, Berlin, 511 pp.

Greuer, C., 1971. Etude ultrastructurale et evolution des cnidocystes de Nematodinium, peridinien Warnoziidae Lindemann. Protistologica 7, 345-355.

Hausmann, K., 1971. Die Trichocysten von Paramecium caudatum. Mikrokosmos 60, 322-327.

- 1972a. Die „Extrusome ${ }^{\text {c }}$ der Protisten. Mikrokosmos 61, 114-117.

- 1972b. Cytologische Studien an Trichocysten. III. Die Feinstruktur ausgeschiedener Mucocysten von Tetrabymena pyriformis. Cytobiologie $5,468-474$.

- 1973a. Cytologische Studien an Trichocysten. IV. Die Feinstruktur ruhender und ausgeschiedener Protrichocysten von Loxopbyllum, Tetrabymena, Prorodon und Lacrymaria. Protistologica (im Druck). 
- 1973b. Cytologische Studien an Trichocysten. V. Zum Ausscheidungsmodus der Mucocysten von Loxophyllum meleagris. Protistologica (im Druck).

- Stockem, W. \& Wohlfahrt-Bottermann, K. E., 1972a. Cytologische Studien an Trichocysten. I. Die Feinstruktur der gestreckten Spindeltrichocyste von Paramecium caudatum. Cytobiologie 5, 208-227.

- - 1972b. Cytologische Studien an Trichocysten. II. Die Feinstruktur ruhender und gehemmter Spindeltrichocysten von Paramecium caudatum. Cytobiologie 5, 228-246.

- - 1973. Cytologische Studien über die Feinstruktur und den Ausschleuderungsmechanismus verschiedener Trichocystentypen. Microscopica Acta (im Druck).

Hovasse, R., 1963. Quelques faits nouveaux concernant les trichocystes et nematocystes des Polykrikos (dinoflagellés). Archs. Zool. exp. gén. 102, 189-198.

- 1965. Trichocystes, corps trichocystoides, cnidocystes et colloblastes. Protoplasmatologia $3,1-57$.

- 1969. Trichocystes ou corps trichocystoides, et nematocystes chez les protistes. Annls Stn biol. Besse-En-Chandesse 4, 245-269.

Jakus, M. A., 1945. The structure and properties of the trichocysts of Paramecium. J. exp. Zool. 100, 457-476.

KrÜGER, F., 1930. Untersuchungen über den Bau und die Funktion der Trichocysten von Paramecium caudatum. Arch. Protistenk. 72, 91-134.

- 1931a. Dunkelfelduntersuchungen über den Bau der Trichocysten von Frontonia Lencas. Arch. Protistenk. 74, 207-235.

- 1931b. Ultramikroskopische Untersuchungen über die nesselkapselähnliche Struktur einiger Trichocysten. Verh. dr. zool. Ges. 34, 139-146.

- 1934a. Bemerkungen über Flagellatentrichocysten. Atch. Protistenk. 83, 321-333.

- 1934b. Untersuchungen über die Trichocysten einiger Prorodon-Arten. Arch. Protistenk. 83, 275-320.

- 1936. Die Trichocysten der Ciliaten im Dunkelfeldbild. Zoologica, Stuttg. 34 (91), 1-83.

KusHida, H., 1961. A styrene methacrylate resin embedding method for ultrathin sectioning. J. Electron Microsc., Chiba Cy. 10, 16-19.

Messer, G. \& Ben-Shaul, Y., 1970. Ultrastructure of aging cells of Peridinium westii. Int. Conf. Electron Microse. 3, 411-412.

- - 1971. Fine structure of tridhocysts fibrils of the dinoflogellate Peridinium westii. J. Ultrastruct. Res. 37, 94-104.

Mignot, J. P., Hovasse, R. \& Joyon, L., 1970. Nouvelles données sur le fonctionement des trichocystes ( $=$ taeniobolocystes) des cryptomonadines. J. Microsc. 9, 127-132.

MülleR, G., 1972. Beiträge zur Methodik und Deutung der Negativkontrastierung. J. Ultrastruct. Res. 39, 77-84.

ReIMER, L., 1967. Elektronenmikroskopische Untersuchungs- und Präparationsmethoden. Springer, Berlin, 598 pp.

Romers, B., 1968. Mikroskopische Technik. Oldenbourg Verl., Mündhen, 757 pp.

Sabatini, D. D., Bensch, K. \& Barnett, R. J., 1963. Cytochemistry and electron microscopy. The preservation of cellular ultrastructure and enzymatic activity by aldehyde fixation. J. Cell Biol. 17, 19-58.

Schmitt, F. O., 1968. In: The molecular basis of life. Ed. by R. H. Haxnes \& P. C. HanaWalt. Freeman, San Francisco, 19-23.

Schuster, F., 1966. Trichocysts of the cryptomonad Cryptomonas truncata. J. Cell Biol. 31, 102.

- 1970. The trichocysts of Chilomonas paramecium. J. Protozool. 17, 521-526.

Seifter, S. \& Gallop, P. M., 1966. In: The proteins, Ed. by H. Neuratr. Acad. Press, New York, 238-304.

Steers, E., Beisson, J. \& Marchesi, V. T., 1969. A structural protein extracted from the trichocyst of Paramecium caudatum. Expl. Cell Res. 57, 392-396.

STOCKEM, W., 1970. Negativ-kontrastierte Trichocysten von Paramecium. Int. Conf. Electron Microscop. 3, 399-400. 
- Komnick, H., 1970. Erfahrung mit der Styrol-Methacrylat-Einbettung als Routinemethode für die Licht- und Elektronenmikroskopie. Mikroskopie 26, 199-203.

- \& Wohlfarth-Bottermann, K. E., 1970. Zur Feinstruktur der Trichocysten von Pardmecium. Cytobiologie 1, 420-436.

SWEENEY, B. M. \& BovCK, G. B., 1966: Crystal-like particles in luminous and non luminous dinoflagellates. In: Bioluminoscence in progress. Ed. by F. H. Johnson \& Y. HANEDA. Princeton Univ. Press, Princeton, N.Y., 331-348.

WoHLFARTH-BotTERMANN, K. E., 1953. Experimentelle und elektronenmikroskopische Untersuchungen zur Funktion der Trichocysten von Paramecium caudatum. Arch. Protistenk. 98, 169-226.

- 1957. Die Kontrastierung tierischer Zellen und Gewebe im Rahmen ihrer elektronenmikroskopischen Untersuduung an ultradünnen Sdhnitten. Naturwissenschaften 44, 287-288.

-- \& Prefrerkorn, G., 1953. Protistenstudien. I. Pro- und Nesselkapseltrichocysten der Ciliaten-Gattung Prorodon. Z. wiss. Mikrosk. 61, 239-248.

Anschrift des Autors: Dipl--Biol. K. Hausmann

Institut für Cytologie und Mikromorphologie

Universität Bonn

53 Bonn 1

Gartenstraße 61a 